\title{
Thinking of People's Health, What about Cassava Crop and By-Products Gluten-Free?
}

ISSN: 2637-7659

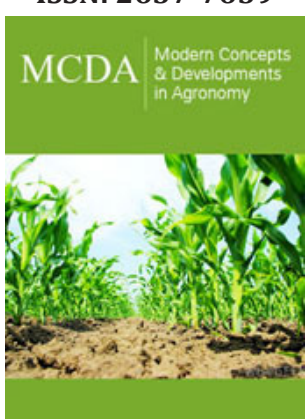

*Corresponding author: $\mathrm{Y}$ Beovides García, Doctor of Biological Sciences and Titular Researcher, Research Institute of Tropical Roots and Tuber Crops (INIVIT), Apdo 6, Santo Domingo, CP 53 000, Villa Clara, Cuba

Submission: 侮July 19, 2021

Published: 㘹July 22, 2021

Volume 9 - Issue 2

How to cite this article: $\mathrm{Y}$ Beovides García. Thinking of People's Health, What about Cassava Crop and ByProducts Gluten-Free? Mod Concep Dev Agrono. 9(2). MCDA. 000706. 2021. DOI: 10.31031/MCDA.2021.09.000706

Copyright@ Y Beovides García. This article is distributed under the terms of the Creative Commons Attribution 4.0 International License, which permits unrestricted use and redistribution provided that the original author and source are credited.

\section{Y Beovides García*}

Doctor of Biological Sciences and Titular Researcher, Research Institute of Tropical Roots and Tuber Crops (INIVIT), Cuba

\section{Opinion}

Covid-19 has shown the weakness of our food and health systems worldwide. After the declaration of the global pandemic, consumers intend to improve their health through making better eating choices and implementing physical activities. Many people are trying to improve their gut health, because a healthy digestive system is associated with a strong immune response. Research have demonstrated that the resistant starch (present in cassava roots) has a substantial advantage over inulin and fructo-oligosaccharides (FOS), because they can be consumed in a higher amount without causing adverse digestive effects, such as gas, bloating or cramps in healthy people recently.

On the other hand, the social isolation and the increase of sick people represent a big challenge for agricultural and marketing systems, because the food demand increase significantly, and some small factories and industries are closed, or they reduced their production levels. We cannot obviate the effect of climate and non-climate stresses; they are impacting the four pillars of food security (access, availability, utilization, and stability), and in this regard, the diversification of the food system is a crucial strategy to reduce risks.

According to the recent Special Report on Climate Change and Land (2019) from the Intergovernmental Panel on Climate Change, the adoption of healthy and sustainable diets, in conjunction with reduction in food loss and waste, can contribute to adaptation through reduction in additional soil area needed for food production and associated food system vulnerabilities. More than 820 million people are undernourished currently, 151 million children under 5 are stunted, 613 million women and girls aged 15 to 49 suffer from iron deficiency, and two billion adults are overweight or obese. We need to find appropriate schemes to face these problems and, at the same time to improve people's life quality, to promote the sustainable development.

Science-based policies are critical for the implementation of adaptation strategies which also take climate variability into consideration. In this sense, various technologies or practices can be developed in current farming operations; many rules, distribution and consumption policies must be checked and changed.

The Food and Agriculture Organization (FAO) has been concerned about the climate change impact and nowadays, with the consequences of Covid-19 on the food safety and on the objectives of sustainable development materialization, especially those millions of people from the world's most vulnerable populations. Food safety is an essential component of the right to adequate food; policy makers should give more attention to guarantee that food safety policies work for all. 
We know that FAO is working for a world free of hunger and malnutrition where food and agriculture contribute to improve the living standards of all, especially the poorest in an economic, social and environmentally sustainable way, but this is not enough. Governments, especially local governments, must work with true and concrete actions to advance in the execution of the objectives of sustainable development for 2030. In a few words, we should understand that we need passion with commitment. In light of this, FAO is promoting the use of cassava and cassava by-products for food, and as alternative ingredients using small-scale technology systems for processing feed. This is an opportunity for me to write about some interesting potentialities of cassava crop and like this, to contribute to a better use of cassava by-products on healthy foods.

But why does FAO promote cassava? Manihot esculenta Crantz (cassava, mandioca or yuca) has contributed in ensuring food and agricultural diversity, livelihoods and food security for centuries. Cassava is one of the main staple food crops grown in the tropics, contributing to a large proportion of the population's daily calories intake in many countries. Millions of people in Latin America, Asia and Africa rely on cassava crop as part of their staple diet. Cassava has many different applications, such as the paper manufacture and cellulose, the bakery, the textile, pharmaceutical and cosmetic industries, fertilizers, in the fuel and minery fields and as food. Based on this, the United Nations (UN) have declared it as the most relevant food from the 21st century.

Dr. Chiedozie Egesi, the program director of NextGen Cassava Breeding project, described this crop: "Cassava is an incredibly useful food and industrial crop today and will be more so, in the future as climate change reshapes agriculture everywhere". The third-largest source of carbohydrates in tropical areas is practically pest free. It can withstand drought and high temperatures, it requires few inputs, and it can grow and produce well, particularly on poor soils, with a wide adaptability to a variety of agro-ecological conditions. Due to this resilience to adverse environmental conditions, cassava has been named as an ideal climate change crop.

This tropical root is cultivated worldwide for the high yield of its storage root containing a high amount of starch, but it is rich in other nutritional components. Cassava leaves can also be consumed, and they are rich in protein, vitamins, minerals and carotenes, but which is the most important characteristic of cassava from the nutritional point of view? Many scientists and health personal coincide on the fact that nutritional benefits of this Pre-Colombian food include the gluten absence in its composition, which make it ideal for people who follow a special diet or have gluten intolerance; it is great for celiac and diabetic persons, and it is also used to heal festering wounds.

On the other hand, we can't obviate that the food industry is interested in the study of some sub-utilized plant species as a contribution to consumers' diet diversification and the incorporation of ingredients with specific technological properties at the present time. Cassava is a traditional crop with an extraordinary demonstrated industrial potential and its industrial uses are steadily growing, because it is becoming an important raw material for a wide number of products. Unfortunately, in spite of its economic and social relevance, it continues as an underutilized product in many countries around the world.

Let's discuss about some cassava by-products. It is rich in carbohydrates; however, such high levels of carbs could mean an insulin spike. If you're looking for a low-carb or low sugar diet, cassava is your best option, that's why cassava flour has a great potential for those on restricted diets, and most closely it replaces wheat flour in cooking and baking. Cassava flour tastes pretty neutral and has a similar texture to wheat with the additional benefit, due to its high amount of vitamin $\mathrm{C}$ and magnesium; it is lower in calories than regular flours, this means less calories with more fiber, and that can keep you satisfied for a long time. The flour itself isn't poisonous. To all these aspects should be given more importance.

Amy Shapiro (master's in clinical nutrition from New York University), dietitian, nutritionist, founder and director of Real Nutrition NYC, summarized this: "Cassava flour is easier to digest than other flours, due to its lighter consistency, as it comes from the root (not from a grain), and it has a high fiber content. The fiber helps to improve regularity and an easy digestion." Furthermore, contrasting with other gluten-free flours like coconut or almond, cassava flour is very pleasant tasting, and it has a powdery and soft texture like the wheat flour.

Important progresses have been achieved and several attempts are underway currently, but the big question continues being: if cassava and by-products gluten-free have all those advantages and good qualities, thinking of people's health, why don't we consume more cassava? why don't we use more cassava?

In my opinion, weak linkages among scientific institutions, government politics, commercial interests, producers and consumers have resulted in uncoordinated efforts to achieve a more successful use of cassava. At the same time, this can be attributed to many factors, but one of them is the lack of knowledge about the advantages and proper ways for using it; more information should be available in all possible ways.

In Latin America and the Caribbean there are good examples of cassava by-products applications. Cassava bread and farine are well known foods of Indigenous peoples from America, especially in Guyana. Both are made from the cassava root after being grated and squeezed dry using a matapee. From there, baking produces the cassava 'bread', while frying produces the farine. Cassava bread or casaba forms part of the culinary identity of Amazon countries, it is a great and surprising food, a survivor who fed several Amerindian indigenous groups, and it is a traditional dish in Cuba and other countries nowadays. Cassava bread or pan de indios, as it is also known, is perhaps the oldest artisanal food on this Caribbean Island, which is linked to its culinary and historical traditions and it is ideal for ensuring food security, as the raw material that doesn't need to be imported. 
As I have explained many times, to eradicate the hunger, more efforts will be carried out to protect rural livelihood and generate equal socioeconomic development, the most important pillar of a healthy food system. That's possible developing resilient crops like cassava with a wide spectrum of applications. Cassava crop can provide diverse, healthy and nutritious foods to face challenges for food security. I think that definitely, cassava has a lot to contribute to the best human nutrition, to agribusiness and as animal feed. I hope producers, investors and consumers understand and support it!

\section{Acknowledgement}

I would like to thank Ms. Geisy Díaz-Roche for her contribution to the revision and comments that greatly improved the original manuscript. Thanks to the Bioali-Cyted network for its technical information support.

\section{Conflicts of interest}

The author declares that he has no conflict of interest.

For possible submissions Click below: 